REVIEW

\title{
Wealth and health: the need for more strategic public health research
}

Fran Baum

J Epidemiol Community Health 2005;59:542-545. doi: 10.1136/jech.2004.021 147

This article argues that public health researchers have often ignored the analysis of wealth in the quest to understand the social determinants of health. Wealth concentration and the inequities in wealth between and within countries are increasing. Despite this scare accurate data are available to assist the analysis of the health impact of this trend. Improved data collection on wealth distribution should be encouraged. Epidemiologists and political economy of health researchers should pay more attention to understanding the dynamics of wealth and its consequences for population health. Policy research to underpin policies designed to reduce inequities in wealth distribution should be intensified.

Correspondence to: Professor F Baum, Department of Public Health, Flinders University, GPO Box 2100, Adelaide 5001, Australia; fran. baum@flinders.edu.au

Received 29 August 2004 Accepted

13 December 2004
$\mathrm{D}$ iscussions about health inequalities and inequities* are most commonly concerned with poverty and its impact on health. The gaze of public health researchers is firmly on who lives in poverty, where, and for how long. The wealthy escape this detailed scrutiny and very rarely feature in causal explanations about why health inequities persist or in policy prescriptions to do something to redress inequities. At a time when the distribution of wealth is growing ever more unequal wealth should become a concern of epidemiologists, health political economists, and social policy makers.

\section{WEALTH DEFINED}

Wealth is defined as things people own and use to (a) produce goods and services (b) enjoy directly without consuming them in the process, examples are-land, natural resources, and shares. ${ }^{1}$ Wealth is distributed in different ways that reflect composition (land, natural resources, produced capital roads, bridges), location (between nations, regions, cities, neighbourhoods, and households), sector (between public, private, and household) and ownership that reflects the distribution of individual private wealth. ${ }^{1}$ Wealth is not the same thing as income. Income is about flow of money whereas wealth is concerned with holding a stock of assets. ${ }^{2}$ Obviously there are strong links between levels of income and wealth but income is not an adequate substitute for understanding the distribution and dynamics of wealth. The patterns of distribution of wealth globally have huge health impacts but they have been largely invisible and unnamed in both broader social science and public health specifically. ${ }^{2}$
Understanding poverty is obviously also important, but is not the focus of this review and some definitions are provided in Kawachi et al. ${ }^{3}$ There are two crucial ways in which wealth affects health status. One is the distribution between people of a country's stock of marketable assets and concerns the wealth of people. The other is the distribution of global wealth between countries and concerns the wealth of nations.

\section{EPIDEMIOLOGY OF WEALTH}

Most public health empirical research is concerned with understanding disadvantage measures income but very little considers wealth. There are better trend data on the distribution of wealth between countries than there are between persons within countries. Analysis of long term trends in world income (which is an indication of wealth) shows that the distance between the richest and poorest country was about 3 to 1 in 1820, 11 to 1 in 1913, 44 to 1 in 1973, and 72 to 1 in $1992 .{ }^{4}$ In 1999 the assets of the 200 richest people in the world were more than the combined income of $41 \%$ of the world's people. ${ }^{4}$ There are very little data on the distribution of wealth between persons within countries. This seems to be because reliable wealth data are elusive. Unless countries have a wealth tax or ask questions in the national census about wealth (which most do not) the information is simply not available or is not very reliable. ${ }^{5}$ Consequently there has been very little epidemiology of wealth distribution or impact on health conducted. Schneider's analysis of the distribution of wealth seems to be one of the first to deal with this topic and public health researchers rarely take such distribution into account in analysis of health inequities. ${ }^{2}$ His analysis of the available data shows that wealth distribution has been persistently unequal. The figures he report differ somewhat according to method of calculation but in all the countries for which he has data-USA, Sweden Australia, Canada, New Zealand, France, West Germany, and Belgium-the top $10 \%$ of people have held at least $50 \%$ of the wealth over the 20th century and the percentage is often higher. A general pattern is that wealth inequality seems to have declined in the first seven decades of the 20th century, but has started to increase from the 1980s, and more so in the 1990s. ${ }^{2}$ A similar

* Inequality is concerned with difference so that equality is about sameness. Inequity is concerned with fairness and ethical considerations stemming from inequalities. The terms are often used interchangeably in the literature on disparities in health status. 
pattern of unequal distribution of wealth exists in each country that Schneider considers. There are some differences in the trends in that Sweden seems to have become more equal in recent years. Despite the paucity of good quality (and consistently measured) data, what is available suggests that the distribution of wealth is more unequal than the distribution of income, and the Gini coefficient for the world distribution of wealth is estimated to be at least as high as $0.9{ }^{2}$ The health consequences of this distribution are likely to be massive, but are as yet uncalculated. From a public policy point of view recent evidence of growing polarisation is worrying. Analysis, based on data from the rich lists published by business magazines, provides some idea of growth in wealth relative to income levels. From such data Stilwell notes that to get on the Rich 100 (compiled by the Australian Business Review Weekly) in 1983 required \$10 million; in 1993 it was \$30 million; and by 2004 it has risen to $\$ 100$ million. ${ }^{6}$ This is a substantial increase well beyond the impact of inflation. From the same database Stilwell notes that the total asset value of the wealthiest 200 Australians rose by $255 \%$ over the past decade. In 1993 the Rich 200 had a total wealth of $\$ 28$ billion compared with nearly $\$ 71.5$ billion in 2004 .

International agencies also produce comparisons of the extent of wealth with the extent of poverty. For instance the WHO noted that, in 1996, just 358 billionaires had a net worth of US\$760m, which equalled the wealth of the poorest $45 \%$ of the entire world's population. ${ }^{7}$ So while a descriptive epidemiology of wealth can be gleaned, the study of wealth has not featured in academic public health research. Most studies focus on income rather than wealth because the data are more readily available. Countries should be encouraged to collect data on wealth and its distribution as a normal aspect of national data reporting.

\section{POLITICAL ECONOMY OF WEALTH}

The political economy of health has also paid only passing attention to the issue of wealth and the wealthy, and has concentrated most attention on poverty and the poor. Yet there are pieces of evidence that suggest public health could advance its overall project of improving population health in an equitable manner by studying wealth more directly. Countries such as those in Scandinavia and Japan have achieved comparatively more equal wealth distribution and also have higher life expectancy than countries with higher overall wealth, but more polarised distribution, such as the USA. Research is needed on the dynamics that lead to this situation. Work on wellbeing and health shows that increasing wealth in rich countries is not necessarily leading to more happiness. ${ }^{8}$ Research on health inequalities is producing more and more evidence that hierarchies are bad for population. ${ }^{9-11}$ Marmot and colleagues found a steady gradient in the rates of death between the lowest and highest ranks of the British civil service. ${ }^{12}$ The main features of his findings were that the gradient was continuous, and that only a third of the effect vanished when lifestyle influences were accounted for. This suggested that the crucial differences were those of status. Given the close link between wealth and status it is highly likely that research into wealth

\section{What this paper adds}

This paper argues that the distribution and impact of wealth has been ignored in most public health research. If public health researchers were to pay attention to it then their analysis would provide a basis for the development of progressive measures to redistribute wealth. and health would show even greater health impacts than is the case with income differentials. There is also a body of evidence on the impact of distribution on income within countries on average life expectancy. The data are somewhat inconclusive, but do show that such macro-level analysis is related to population health outcomes. A recent review of the evidence by Lynch and colleagues was noticeable in that no studies of wealth distribution were reviewed..$^{13}$ Finally, there is a body of evidence from developing countries that shows that achieving high levels of population health does not necessarily require high national wealth. ${ }^{14}{ }^{15} \mathrm{Cuba}$, Sri Lanka, China, Kerala State in India, and Costa Rica are all examples of places where high health has been achieved despite the fact that they have much less wealth than other countries. Analyses suggest that such achievements result from social investment in literacy, education, protecting the livelihoods of small farmers, good primary health care services, and meeting basic needs. These factors add up to societies where social solidarity and the goal of egalitarianism are favoured over an ethic of individualism, which is more strongly emphasised by neo-liberal regimes. The importance of these studies is to show that achieving a decent standard of living for all the world's population is primarily a question of the politics of distribution not of insufficient resources. Recent evidence from China suggests that as the more egalitarian regime gives way to a more capitalist enterprise, disparities in health and economics are increasing. ${ }^{16}$ The epidemiology of wealth that is available suggests that in the period of growing welfare investment by states, wealth distribution becomes a little more equal. ${ }^{2}$ By contrast, the past decades of rampant neo-liberalism, with the concomitant withdrawal from welfare, seem to have increased inequality in distribution.

\section{Policy implications}

- Analysis of the distribution and concentration of wealth and its impact on health would assist policy makers in devising taxation and other policy to redistribute wealth in such a way as to increase overall population health status.

- Research funding bodies should fund public health research that examines the health costs and benefits of inequities in wealth between people within countries and between countries.

- National governments should consider increasing taxes on wealthy people through means such as death duties and estate taxes and invest the money gained from these taxes into public goods such as public health services and public education.

- International bodies such as the World Bank, International Monetary Fund, and the World Health Organisation should consider means of redistributing wealth globally so that the current vast inequities between high and low and middle income countries are reduced. Measures already proposed are a Tobin type tax on investment transaction, tax on air travel, increased taxes for transnational corporations.

- Public health associations and other public health lobby groups should develop advocacy strategies in relation to excessive wealth in addition to those concerned with poverty reduction. Their lobbying and advocacy should report the extent of wealth inequity and describe what population health gains are likely to be gained if a proportion of wealth is re-distributed. 
Most research on health inequalities has been conducted in rich countries considering disparities within those countries. Very little has been conducted on health inequalities (and even less on inequities) within middle or low income countries. Yet it is often in such countries that the disparities of both income and wealth are most extreme. Very little consideration has been given to considering the implications of these inequalities for health and development in poor countries. There is currently very little understanding of how the huge disparities in income and wealth between rich and poor countries themselves contribute to the massive health inequalities that see 20 to 30 years life expectancy difference between those in rich and those in poor countries. The conclusions from rich country research that being lower down in a hierarchy is stressful to the body, and so has an impact on life expectancy, ${ }^{17}$ must surely affect these massive health inequalities between rich and poor countries, and yet the global social relations stemming from unfair resources distribution and trading patterns have not been researched. What is the public impact of consumption patterns created by egregious wealth on diet, the use of fossil fuels, and of water, for example? There is an emerging body of evidence on the impact of unfair trade practices on the health of people in poor countries ${ }^{18} 19$ and a growing civil society protest against unfair trade. ${ }^{20}{ }^{21}$ While some research attention is being paid to the ways in which rich countries establish financing and trading structures to maintain their privilege (such as the International Monetary Fund and the World Bank), there is scope for much more research of this type.

\section{POLICIES TO REDUCE WEALTH INEQUITIES}

Building an evidence base on wealth and health, and on understanding the dynamics underpinning the distribution of wealth and health, could be complemented by policy research that considers what healthy public policies seeking to redress undue concentration of wealth might look like. This research could consider comparative analysis of social attitudes towards wealth and social solidarity. The current extreme disparities in wealth (both within countries and between countries) can continue to exist only because there is general ideological support for it. Clearly, there is a need for research into the function that wealth and income inequality play in the global economic system. The acceptability of equal wealth distribution differs from society to society and from one time period to another. Studies of the conditions that bring about relative equity would be valuable to understand how redistributive policies can be achieved. Part of the ideological support for the acceptability of large discrepancies in wealth must in part be explained by the need to encourage widespread consumerism. A consumerist ethic is underpinned by the status that is derived from material goods that are outward expressions of a person's material success through wealth accumulation. The implications for ecological sustainability, and so global health, of unfettered consumerism, are further aspects of unquestioned wealth that deserve more research attention. Pond and Popay spoke two decades ago of an "ideology of inequality" that was accepted as consensus and as necessary to underpin a successful economy. ${ }^{22}$ Since then this ideology seems to have become more entrenched with the onslaught of neo-liberalism. The growth of global corporations with budgets larger than smaller countries fuels the ideology of wealth creation. ${ }^{23}$ Yet little research has been systematically devoted to understanding the impacts of neo-liberalism and the inequities in wealth it underpins on population health outcomes. Similarly there has been little research on the public health benefits of societies that manage to establish comparatively higher social solidarity.
Further research could also analyse taxation policies on income and wealth from a public health perspective. Consideration could be given to the potential public health impact of general wealth tax, capital gains tax, capital transfer tax, and death taxes. The proceeds from these taxes could be invested by the state in infrastructure such as publicly funded health and education services that would act to reduce health inequities over the longer term. A small proportion from developed countries could be invested as overseas aid to go some way towards redressing the huge differences in wealth between rich and poor countries. Similarly, a Tobin tax has been floated as a method of discouraging short term currency trade, a means by which wealth is accumulated. ${ }^{24}$ The imposition of this tax could have significant public health benefits if its proceeds were invested into international priorities to promote wellbeing and health, and reduce inequality. Ackerman and Alscott note the growing inequalities in wealth in the United States of America and call for a $2 \%$ tax on wealth (including stocks, bonds, bank accounts, houses, cars, family firms, and pensions) over a certain level. ${ }^{25}$ They would use the proceeds to provide all young US citizens with a financial lump sum and so make them "stakeholders". The population health implications of such proposals should be assessed. At a broader level, this policy research could compare the population health and wellbeing achieved in societies with differing socioeconomic arrangements, for example to compare and contrast societies with strong welfare states with those that emphasise a more neo-liberal approach to state intervention to redress market inequities. For one of the rare examples of this type of research see Navarro. ${ }^{26}$ Increasing calls are being made by civil society groups such as the People's Health Movement ${ }^{27}$ and the Jubilee Debt Campaign ${ }^{28}$ for a re-assessment of the global terms of trade, and the debts that are so crippling to poor countries. The terms of trade are fundamentally biased in favour of rich countries, and work both to underpin wealth accumulation in high income countries. ${ }^{19}$ and threaten the livelihood of groups such as small farmers in poor countries. A detailed understanding of historical and contemporary global trading patterns is essential to understand current patterns of wealth and health inequities. Public health research agenda are beginning to embrace research on the political economic patterns underpinning health and illness, but globally only very tiny research budgets are devoted to these questions. The importance of increasing research on the upstream determinants of health was recognised at the 2004 meeting of the Global Forum for Health Research. The dynamics of wealth distribution and their impact on health inequities are central issues for a global research agenda committed to a more equitable world.

\section{CONCLUSION}

Wealth has been on the sidelines of public health research and policy for too long. A greater concentration of research effort on its dynamics and distribution promises to lead to greater understanding of the causes of health inequalities, and provide a basis for the formulation of polices to address these factors.

\section{ACKNOWLEDGEMENTS}

Thanks to Professor Gavin Mooney for helpful comment on an earlier draft of this article. Thanks also to the three reviewers (David Legge, Ioannis D K Dimoliatis, Jennie Popay) each of whom made helpful comments that have improved the arguments in this paper.

Funding: none.

Conflicts of interest: none declared. 


\section{REFERENCES}

Stretton H. Economics: a new introduction. Sydney: University of New South Wales Press, 2000:41-2.

2 Schneider M. The distribution of wealth. Cheltenham, UK: Edward Elgar, 2004.

3 Kawachi I, Subramanian SV, Almeida-Filho N. A glossary for health inequalities. J Epidemiol Community Health 2002;56:647-52.

4 United Nations Development Programme Globalization with a human face. Human Development Report 1999. http://hdr.undp.org/reports/global/ 1999/en/ (accessed 20 Nov 2004)

5 Stilwell F, Ansari, M. Wealthy Australians. Australian Political Economy 2003;52:143

6 Stilwell F. Tall poppies on the march. Business Review Weekly 2004; May 20-26:88

7 World Health Organisation. Health and environment in sustainable development: five years after the Earth Summit Geneva: WHO, 1997.

8 Eckersley R. Well and good. How we feel and why it matters. Melbourne: Text Publishing, 2004:77-125.

9 Wilkinson RG. Income distribution and life expectancy. BMJ 1992;304:165

10 Wilkinson RG. Unhealthy societies. The afflictions of inequality. London: Routledge, 1996.

11 Kennedy BP, Kawachi I, Glass R, et al. Income distribution, socioeconomic status and self-rated health in the United States: multilevel analysis. BM. 1998;317:917-21.

12 Marmot M. Introduction. In: Marmot M, Wilkinson RG. Social determinants of health. Oxford: Oxford University Press, 1999:1-16.

13 Lynch J, Davey Smith G, Harper S, et al. Is income inequality a determinant of population health? Part 1 A systematic review. Millbank Mem $Q$ 2004;82:5-99.

14 Werner D, Sanders D. Questioning the solution: the politics of primary health care and child survival. Palo Alto, CA: Health Rights, 1997:114-18.
15 Halstead SB, Walsh JA, Warren KS, eds. Good health at a low cost (a conference report). New York: The Rockefeller Foundation, 1985.

16 Smith CJ. (Over)eating success: the health consequences of the restoration of capitalism in rural China. Soc Sci Med 1993;37:761-70.

17 Brunner E, Marmot M. Social organisation, stress and health. In: Marmot M, Wilkinson RG. Social determinants of health. Oxford: Oxford University Press, 1999:17-43.

18 Labonte R, Schrecker T. Committed to health for all? How the G7/G8 rate? Soc Sci Med 2004:59:1661-76.

19 Labonte R, Schrecker T, Sanders D, et al. Fatal indifference. The G8 Africa and global health. Cape Town: UCT Press, 2004

20 People's Health Movement. http://www.phmovement.org (accessed 19 Aug 2004).

21 World Social Forum. http://www.wsfindia.org/ and http:// www.portoalegre2003.org/publique/ (accessed 19 Aug 2004)

22 Pond C, Popay J. Tackling inequalities at their source. In: Glennerster H, ed. The future of the welfare state. Remaking social policy. London: Heinemann Educational, 1983:115.

23 Korten D. When corporations rule the world. London: Earthscan, 1995

24 Tobin Tax Initiative. http://www.ceedweb.org/iirp/ (accessed 19 Aug 2004).

25 Ackerman B, Alstott A. The stakeholder society. New Haven: Yale University Press, 1999:94-112.

26 Navarro V. Neoliberalism, "globalization", unemployment, inequalities, and the welfare state. In: The political economy of social inequalities. Consequences for health and quality of life. Amityville, NY: Baywood Publishing, 2002:33-107.

27 People's Health Movement. http://www.phmovement.net laccessed 25 Nov 2004).

28 Jubilee Debt Campaign. (http://www.jubileedebtcampaign.org.uk/ (accessed 23 Nov 2004).

\section{THE JECH GALLERY}

\section{Sanitation, sanitation, sanitation}

- dwin Chadwick, pioneer of public - health at the national level in England - in the 1840s, held strongly to the mantra that it was necessary to find the best way of doing something and to do it everywhere. One of his most long lasting memorials has been the brick-lined egg-shaped sewer. Earlier sewage systems, which had replaced earth privies or over-water latrines (picture from Lancashire from the 1980s, albeit plumbed in!) had suffered from their square shape tendency to back up. The dynamics of egg-shaped sewers created sufficient pressure to maintain a flow at most times. These systems, pioneered by Newlands, Liverpool's borough engineer, have stood the test of time and are currently being re-lined with these composition inserts throughout the United Kingdom (pictured top right).

John R Ashton

North West Public Health Team, Department of Health, 18th Floor, Sunley Tower, Piccadilly Plaza, Manchester MI 4BE, UK; johnrashton@blueyonder.co.uk
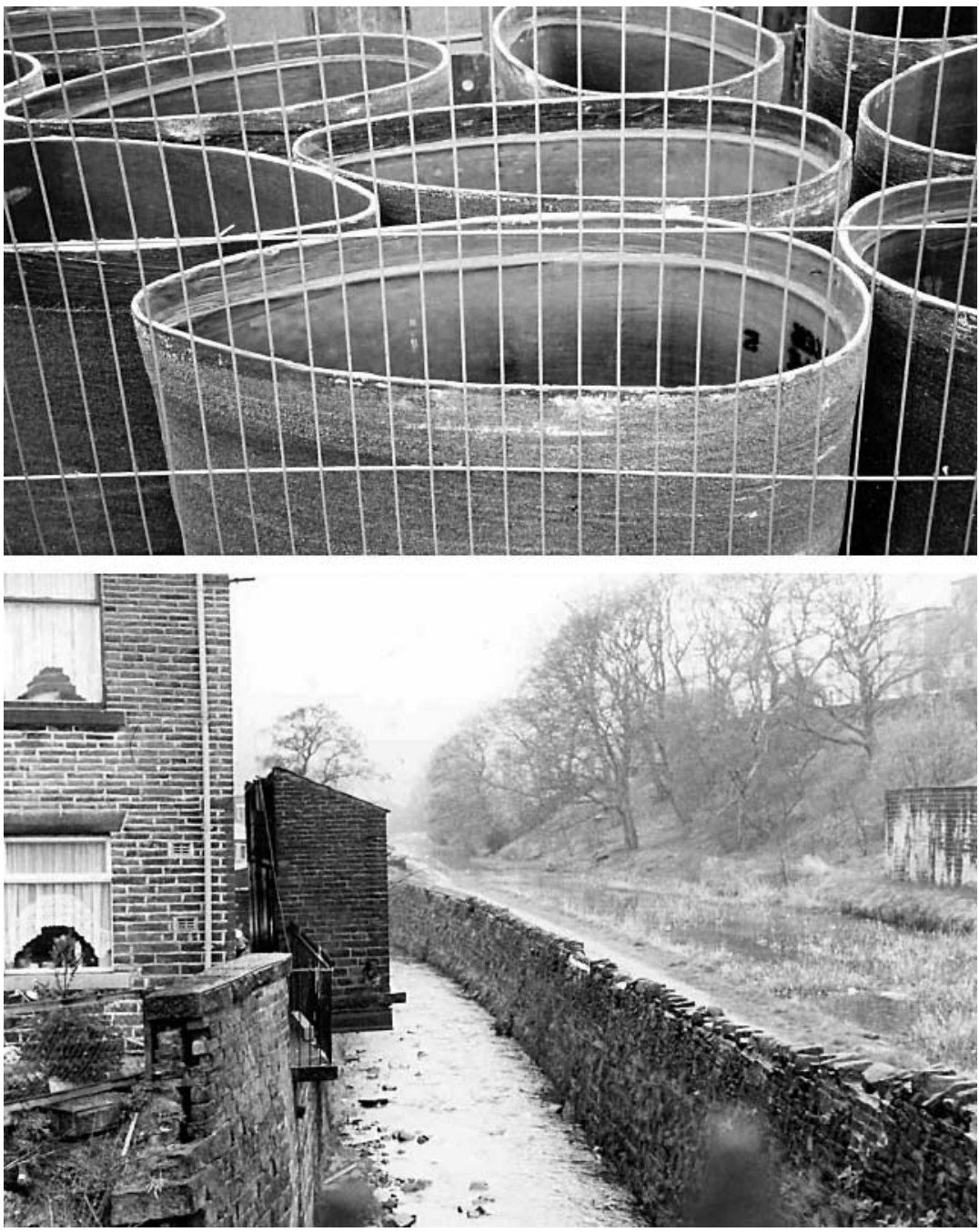